\title{
University of San Francisco
}

From the SelectedWorks of Thomas A. Maier

Winter December, 2011

\section{Evaluating the Alignment of Academic Research and Industry Leadership Best Practices}

Thomas A. Maier, DePaul University 


\begin{abstract}
This hospitality leadership research analysis was conducted in order to assess the alignment of academic research and industry leadership best practices. Research findings suggest that industry leadership best practices reported are inconsistent with the emphasis in the academic literature. Most notably, academic literature reviewed for this study identified leadership dimensions associate with; bureaucratic, transformationalparticipative, generational change and emotional intelligence as of particular importance with respect to workforce performance, while industry leaders identified brand differentiation, business acumen, learning environments or lack thereof as a concern when operating in a highly competitive marketplace. Future academic research surrounding the topic of leadership in hospitality should be more closely embedded with industry leaders and their desire to improve leadership capabilities while preparing hospitality student readiness for industry placement that strengthens organizational performance in our rapidly changing global economy.
\end{abstract}

Keywords: Hospitality leadership, academic research, industry best practices 


\section{Introduction}

Effective leadership in the lodging industry is essential in achieving financial results and realizing desired performance objectives. Given the complexity of leadership in today's hotel-lodging marketplace intensifies the need for examination of current issues in academic research and industry based leadership practices. This study examines the alignment of hospitality leadership research and industry leadership best practices for the purpose of informing both academic and industry stakeholders. A literature review of academic and trade publications in the lodging sector provides a baseline understanding of the current discussion among and between academics and industry leaders.

In today's marketplace the majority of companies in the hotel-lodging industry operate within large-scale, bureaucratic leadership structure with communication and flow of information in a highly structured and formalized manner (Lucas and Deery, 2004). Leadership is usually top-down and transactional, focused on reacting to and solving problems. Many popular hotel chains (i.e.; Marriott Corporation, Holiday Inn, Starwood Hotels, and Harrah's) have achieved success with a hierarchy based leadership approach to operational performance and service delivery.

Literature examining the topic of leadership within the academy focuses on the following dimensions; (1) bureaucratic leadership, (2) transformational-participative leadership, (3) generational leadership, (4) workforce engagement, and (5) emotional intelligence. Literature surrounding the topic of leadership among hotel-lodging leaders indicates the industry focuses on the following leadership dimensions and best practices; (1) business acumen-learning environments, (2) work-life balance, (3) loyalty programming, (4) branding-co-branding, and (5) social media-mobile technology. This analysis uncovers the most significant discrepancies between the way leadership is practiced in the hotel-lodging industry and how hospitality academic research suggests it should be. There are three objectives of this leadership research analysis: First, to provide useful information to lodging organizations regarding the most critical approaches and practices of leadership necessary to achieve quality service delivery objectives. Second, provide valuable information pertaining to changing workforce demographics and multigenerational perspectives of leadership. Thirdly, information was gathered from top ranked referred journals to compare and contrast leadership best practices provided by academic professionals to those of hotel-lodging industry leading firms.

\section{Literature Review}

Closer examination of hospitality leadership practices can illuminate both academic researchers and industry professionals through improved focus and enhanced operational performance. Several hospitality leadership research studies from 1994-2011 were analyzed to ascertain the current scope and range of leadership research topics within the hospitality academy and compare those to leadership best practices identified by current industry leaders.

\section{Insert Table 1}




\section{Bureaucratic leadership}

In consideration of Table 1, a review of the research indicates the prevalent leadership approach used in the hospitality industry is based on the principals of top-down bureaucratic leadership with an emphasis on cost-driven policies that view employees as human capital resources necessary to achieve organizational goals. Researchers state that a bureaucratic approach to management often disregards the aspirations, expectations, and needs of individual employees (Pitaway, Carmouche and Chell, 1998; Lucas and Deery, 2004; Mok et al., 1998; Tracey and Hinkin, 1994, 1996). In a global economy with diverse workforces, and lean staffing levels, this leadership approach may be less effective in achieving organizational goals, retaining employees long term, and fostering collaborative efforts that are realized in sustained profits.

Lucas and Deery (2004) argue many hospitality companies utilize the principles of top-down bureaucratic leadership framework with a focus on cost-driven human resource policies where employees are treated as another resource to be deployed in order to achieve organizational goals. Researchers have reported that typically in a bureaucratic system; the absence of effective leadership causes disregard for the feelings, aspirations, personal goals, need for self-fulfillment, satisfaction, and the potential for development of employees results in lost efficiency, productivity, and profit (Lucas \& Deery, 2004; Ogaard et al., 2007; Ross, 1994). Additionally, Hinkin and Tracey, (2000) present evidence supporting the contention that ineffective leadership can unfavorably contribute to employee turnover rates as high as $60 \%$, low job satisfaction, and declining service quality.

\section{Generational leadership}

Gursoy, et al., (2008) propose that the bureaucratic leadership approach pervasive in hospitality organizations today, is no longer effective in leading a workforce that is increasingly multigenerational. Similarly, Zemke et al., (2000) argues it is crucial for hospitality leaders to understand multi-generational similarities and differences in worldviews, attitudes, work philosophy, and ways of interacting with others; because it enables them to make informed decisions in creating positive working conditions that attract and retain highly productive workers and delivery of quality services.

Since the hospitality industry is staffed by a multigenerational workforce current leadership theory pertaining to multi-generations underscores the necessity of understanding how key factors affect the ability of multigenerational workforce leaders to achieve organizational goals. Ogaard, Marnburg, and Larsen, (2007); Uhl-Bien, Marion, and McKelvey, (2007) have indicated these factors include: (1) flattening of bureaucratic organizational structures, (2) transitioning of information acquisition from seeking the wisdom of older colleagues to utilizing information technology. Furthermore, Minett, Yaman, and Deniczki, (2009) find that Baby boomer hospitality leaders are more likely to use democratic-transformational leadership approaches as their preferred leadership style, although female Baby boomers are less likely to use transformational leadership overall. King, Funk and Wilkins, (2011) report older generational leaders (baby boomers) feel a need to micro-manage millennial generation employees because of the increased 


\section{Educational Research}

emphasis on cutting operating costs while delivering quality service. They also acknowledge the difficulty in leading millennial employees because of their desire for upward mobility and rapid promotion.

Cairncross and Buultjens, (2007) present generational leadership research findings that focus on the importance of embracing and integrating the technological savyness of millennials in order to increase their productivity and overall contributions to the organization. They emphasis the importance of creating job variety, open access to coworkers, and project based work flow that allows millennials to frequently interact with others in the organization. Most importantly, they indicate the importance of training to millennials, and those around them. They propose millennials need training for knowledge development while others around them need training to better understand millennials characteristics and behaviors in the workplace.

\section{Transformational-participative leadership}

Gill et al., (2009) introduce transformational leadership as favorable means of tapping into employees desire for empowerment. They contend greater levels of empowerment generate higher performance in customer service delivery. They contend transformational leaders are effective because they possess effective listening skills, are capable of recognizing and overcoming cultural barriers, and place a premium on fostering upward rather than downward communication. Masry, Kattara, and Demerdash, (2004) also make a study on which emphasizes the benefits of participative leadership approach as an effective means to empower employees. They indicate in their findings that a more participative leadership approach fosters greater engagement and endorse the substitution of bureaucratic-autocratic leadership with a participative-democratic style. In their research findings, Kozak and Uka, (2008) support the contention that hospitality leaders who use a more democratic and participatory leadership approach view their employees from a humanistic versus bureaucratic approach. They present findings that indicate those hotel general mangers that are more educated tend to use a more democratic-participatory approach to leadership.

\section{Workforce engagement}

A key component of a leadership within the hospitality industry remains workforce engagement. The social milieu and key historical events that are shared among groups influences attitudes about work, job commitment, co-worker and employee-leader interactions, and preferred leadership style (Kupperschmidt, 2000; Smola and Sutton, 2002). Employees' engagement levels appreciably influence job satisfaction and commitment to work and therefore have received considerable attention by researchers in the hospitality industry (Chu, 2007; Kim, Chin, and Umbreit, 2007; White, 2006). The values that workers hold are strongly influenced by the generation they were born. These values people hold have cognitive, affective and behavioral dimensions that are closely linked to engagement and satisfaction (White, 2006). Brown (2002) and Chu (2007) explored the relationships that attitudes and behaviors have on worker engagement among hospitality workers. Chu (2007) argued that within the hospitality industry, understanding employees' values is important in increasing levels of engagement because these values affect worker attitudes towards their jobs and the customers they serve. 


\section{Educational Research}

\section{Emotional intelligence}

Researchers have found strong linkage between Emotional Intelligence and quality service. Sosik \& Megerian, (1999); Wong \& Law, (2002) reported front-line employees need to be nurtured and feel supported in order to deliver high quality service. Kim and Argusa, (2011) discuss the relationship of high emotional intelligence levels among hospitality workers and their task-oriented coping behaviors. Interestingly enough, they argue the ability of Baby boomers to cope with task orientation better than other generational cohorts and recommend hospitality industry leaders focus on recruitment of baby boomers for their high emotional intelligence capabilities. Langhorn, (2004) formulates a favorable view of emotional intelligence that links leader emotional intelligence with:(1) customer satisfaction, (2) profit performance, (3) high appraisal rating, and (4) team satisfaction.

\section{Hospitality -Lodging Industry Leadership Best Practices}

Effectively leading a changing workforce begins with an examination of the management and leadership styles that are prevalent in the hospitality industry. Hospitality industry leaders have implemented a variety of activities in their organizations to facilitate excellence in performance that include: (a) leveraging leadership capability, (b) self-directed team approaches, (c) green practices, (d) customer service programming, (e) diversity training, and (f) guest-loyalty programs. Disney, Marriott, and Day Hospitality are examples of hospitality corporations that have successfully implemented industry best practices. Based on information presented by the Walt Disney Corporation on the People Management section of the DisneyInstitute.com website, the following best practices adopted by the corporation in facilitating a productive work environment coupled with high quality customer services is summarized.

\section{Insert Table 2}

In view of Table 2, there are several industry best practices that have been identified in both the trade/industry publications and the academic literature. The Walt Disney Resort in Orlando, Florida, known for its customer service, employees over 50,000 workers, and is the largest single site employer in the US. The mission of the Disney Corporation is to provide high quality resort accommodations with exceptional customer service. The employees are the foundation to realizing this mission. According to Walt Disney, "You can dream, create, design and build the most wonderful place in the world, but it requires people to make the dream a reality" (DisneyInstitute.com, People Management section). While low employee retention is a serious problem in the hospitality industry, employee retention is one of Disney's success stories. Based on the philosophy and work culture envisioned by Walt Disney, the leaders of the Disney Corporation have implemented best practices that continue to create a work environment that facilitates both employee loyalty and retention.

First, maintaining high levels of retention begin during the applicant screening and hiring process. Human resource personnel select applicants who not only have the skills 


\section{Educational Research}

necessary for the position but appear to be a good fit with Disney's organizational culture (DisneyInstitute.com, People Management section). Second, structuring around adherence to high employee standards leaders have implemented a service plan that integrates high service standards supported by a delivery system that promotes exceptional quality. Workers are considered cast members that are "On stage" when working directly with Disney customers and "Back stage" when working behind the scenes. Finally, it has been a long held belief by Disney leaders that employee retention is tied to training employees when they first enter the corporate workforce and providing opportunities for workers to improve their performance throughout their careers with the company.

Disney Leaders also incorporate leadership approaches that promote worker investment in the vision and mission of the Walt Disney Corporation. At Walt Disney, leaders focus on creating a work environment and processes that facilitate consistently high quality customer service based on the following tenets:

1. Engage employees in the company culture. Vital to the management of an organization's employees is the communication and nurturing of the company's culture that facilitates employee communication at all levels of the organization.

2. Provide a supportive work environment that celebrates success. From recruiting to career management, employees want to know what is expected of them and how their managers and other leaders of the company will communicate corporate performance and service expectations.

3. Inspire employees to meet organizational and performance goals by engaging workers in the rich traditions and shared values that are tied to high quality standards.

These best practices have consistently produced results in leading a workforce with lower turnover rates than is typically experienced by other hospitality entities.

Marriott Corporation is a multinational corporation well known for their global brand image of quality product and service delivery. Leaders have made progress in decreasing employee turnover and increasing retention by implementing a program for leveraging leadership capability (Enz \& Siguaw, 2003) while offering development and growth opportunities for the workforce. "This included the development of core competency 'buckets' by senior managers to help identify managerial talent within the organization. The core competencies included: (a) business acumen, (b) relationship building awareness, and (c) learning and applying expertise" (p. 116).

To reduce turnover and engage their workforce, leaders at Day hospitality- made changes within the organization to address a growing desire among their employees to find a balance between their work-life and life outside of the company (Enz and Sigauw, 2003). These leaders implemented a mandatory 90 -day sabbatical leave program for all property general managers and corporate staff who had accumulated at least five years of continuous service.

As part of their "ambition 2015" objective leaders at Carlson Hotels have embarked upon an aggressive growth plan that included strategic leadership focus on the following components, AAHOA Lodging business (2011): 


\section{Educational Research}

1. Social responsibility in terms of the environment and being involved in their communities.

2. Expanding Branding-co-branding opportunities through new retail and restaurant partners to add loyalty redemption opportunities with iTunes, Best Buy, T.G.I Fridays. Introduction of a new app for iPhone and android consumers.

3. Introduction of a new loyalty program designed to attract new members through worldwide resort product offerings and low point redemption values.

\section{Discrepancies Among Academic Research Surrounding Leadership Practices}

Research surrounding a bureaucratic approach to leadership indicates several discrepancies between (Minett, D., Yaman, H.R, \& Denizci, B. 2009) and (Kozak and Uka, 2008) and (Borgatti, 2002). Minett et.al, (2009) contend the prevalent leadership style in successful hospitality industries today reflect a bureaucratic style and use of a utilitarian or rule based decision making-style. Conversely, Kozak and Uka, 2008 argue the importance of hospitality leaders deployment of a more democratic and participatory leadership approach that takes into account a more human view of employees incorporating their goals, aspirations and needs versus a bureaucratic approach. According to Borgatti, (1996) command-and-control leadership and bureaucracy cuts the company leader off from the views and criticism of the front-line workers and managers, leaving subordinate workers feeling isolated, unheard, and treated as objects used to meet organizational goals. Moreover, research presented by (Gursoy \& Swanger, 2007) emphasizes the understanding and application of proper "fit" between leadership approach and organizational bureaucracy. They contend it has been shown to produce more efficient and effective companies in terms of their visions, missions, goals, and objectives. Gursoy and Swanger (2007) suggest that to facilitate improved performance and quality of service in the hospitality industry, leaders need to gain an in-depth understanding of how organizational functioning (bureaucracy) works best, particularly between various generational groupings

Research discrepancies pertaining to generational leadership issues deal with reported findings surrounding the millennial generation. Discrepancies have been uncovered between (King, Funk and Wilkins, 2011) and (Kim and Argusa, 2011). King, Funk, and Wilkins (2011) propose younger generations (millennial) expect quick upward mobility; they propose managing millennials via an introspective transformational leadership approach. Conversely, Kim and Argusa , (2011) propose millennial generation workers are less able to cope using task-oriented, emotionally intelligent approaches, they contend hospitality leaders should focus on hiring older generation workers (baby boomers) because they (Kim and Argusa) view millennials as scare in the workforce. Furthermore, generational leadership discrepancies exist between (King, Funk \& Wilkins, 2011) and (Cairncross \& Buultjens, 2007). King et. al, (2011) suggest difficulties in managing millennial generation workers; Kim and Argusa, (2011) even recommend hiring older baby boomer workers because they have better emotional intelligence. Conversely, (Cairncross \& Buultjens 2007) view millennial generation workers as an untapped resource; they find that most hospitality managers still actively recruit millennial workers and believe leaders must find ways to best manage them, and make organizations adapt to their needs. 


\section{Educational Research}

Currently, the majority of companies in the hospitality industry continue to operate within large-scale organizational structures with communication and the flow of information moving downward from the top in a highly formalized and rigid manner. Leadership is usually top-down and transactional, focused on reacting to rather than being proactive in solving problems. Many popular hotel chains (i.e., Holiday Inn, RLH Corporation, Starwood Hotels, and Harrah's) have achieved success with the hierarchy based autocratic leadership structures and top-down approach to leadership. This would be inconsistent with the academic literature identified, which indicates a strong preference given to transformational and participative leadership approaches. For instance, (Enz \& Siguaw, 2003) revealed hospitality leaders are constantly looking for ways to attract and retain workers because potential employees are attracted to those organizations that devise new ideas and ways of transforming the business and the work environment to be more exciting, rewarding and engaging. Conversely, Brown, (2011) reports transformational leadership traits indicated no direct relationship between leaders dimensions and employee performance. In his study of 34 hotels in the Midwest, findings indicated transformational leaders exhibited inspirational motivation and idealized influence more frequently than intellectual stimulation. However, no direct correlation between these transformational leadership dimensions and improved employee performance was evident. In contrast, Sosik \& Megerian, (1999); Wong \& Law, (2002) reported front-line employees need to be nurtured and feel supported in order to deliver high quality service.

Consistent with a transformational leadership approach and at odds with current industry practice (Kupperschmidt, 2000; Smola and Sutton, 2002) argued employees' engagement levels appreciably influence job satisfaction and commitment to work. Their view of leadership is based on a more open organizational environment with higher levels of transparency and democratic principles. Additionally, transformational leadership has been linked to emotional intelligence as reported by Halsell-Scott, (2008). In her study she indicated successful leaders in the hospitality workplace possess transformational leadership traits that include; teamwork, collaboration, and excellent interpersonal communication. She posits certain emotional intelligence dimensions are necessary in order to possess effective transformational leadership skills. Research surrounding emotional intelligence deals primarily with age related findings. In this regards, discrepancies exist between (Kim and Argusa, 2011) and (Langhorn, 2004). Kim and Argusa, (2011) posit older hospitality employees display greater emotional intelligence, particularly better coping mechanisms. Conversely, Langhorn, (2004) assert that age related emotional intelligence is not significant in business performance. Rather, Langhorn, (2004) formulates a favorable view of emotional intelligence that links leader emotional intelligence with:(1) customer satisfaction, (2) profit performance, (3) high appraisal rating, and (4) team satisfaction.

\section{Discrepancies Between Academic Research and Industry Leadership Best Practices}

This comparative research analysis examined the extent to which academy and industry leadership practices are in alignment. Table 3 illustrates the gaps identified in the leadership research articles reviewed and reflects poor alignment between the academy and industry. The findings of this study suggest that, moving forward, the hospitality 


\section{Educational Research}

sector is focused on leadership issues that relate to the core themes of; business acumen, brand management and social media technology, whereas, the academy is focused on leadership themes surrounding; leadership styles and approaches, workforce engagement and emotional intelligence.

\section{Insert Table 3}

\section{Providing a Better Alignment Between Academic Research and Industry Practice}

The objectives of this leadership research analysis were to provide useful information to hospitality organizations regarding the most critical approaches and practices of leadership necessary to achieve quality service delivery objectives. In that regard, there is no clear indication or consensus among academics of a single leadership style or approach that encompasses all the emerging issues surrounding workforce development and customer service. Notably, generational perspectives of leadership are gaining more attention in the literature, particularly surrounding the millennial generation and the best way to connect with them in the workplace. However, industry leaders have yet to identify this as a top priority in their strategic planning. Additionally, information was gathered from top ranked referred journals and trade publications to compare and contrast leadership best practices provided by academic professionals to those of leading hotellodging industry firms. Significant gaps were identified in terms of academic and industry alignment as it relates to leadership and leadership practice. The primary focus of the academic research reviewed has been grounded in leadership styles and approaches pertaining to internal performance competency, namely dealing with generational differences and workforce engagement. Conversely, Industry leadership practices reviewed focused on forward thinking technology and innovation associated with social media, brand positioning/development and customer service delivery.

Ideally, academic leadership research and leadership industry practice should have a symbiotic orientation. Today, the topic of leadership and leadership development is finding its way into hospitality curriculum development with greater importance and focus. Continued hospitality leadership-centric research is likely to enhance both curriculum development and industry readiness for future hospitality professionals. Moreover, within the academy, a comprehensive focus on leadership dimensions, both internal and external, and their relevance to industry needs could prove invaluable to industry leaders. The more integration of applied academic research into industry practice the increased likelihood of improved job placement for future student graduates, improved access for researchers to relevant data, potential industry funding sources and the contemporary evolution of hospitality curriculum. This research analysis provides a "snapshot" view of academic and industry related leadership dimensions. Future academic research surrounding the topic of leadership in hospitality should be more closely embedded with industry leaders and their desire to improve leadership capabilities while preparing hospitality student readiness for industry placement that strengthens organizational performance in our rapidly changing global economy. 
Examination of Hotel-Lodging Academic and Industry Leadership Practices in 10 Educational Research

\section{References}

Borgatti, S.P. (2002). Bureaucracy. Retrieved online June 2, 2011 from http://www.analyctech.com/mb021/bureau.html

Brown, D. (2002). The role of work and cultural values in occupational choice, satisfaction, and success: a theoretical statement. Journal of Counseling and Development 80, 48-55.

Brown, E.A. (2011). Perceptions of transformational leadership behaviors and subordinates performance in hotels. Journal of Human Resources in Hospitality \& Tourism, 10(1) 45.

Cairncross, G. \& Buultjens, J. (2007). Generation Y and innovator employers in the Australian tourism and hospitality industry. Journal of Economic and Social Policy, 12(1), 3-24.

Chu, K. H. (2007). A factorial validation of work value structure: Second-order confirmatory factor analysis and its implications. Tourism Management, 29(2), 320-330.

Disney Institute. (2010). People Management section. Retrieved online December 27, 2010 from http://www.disneyinstitute.com/Topics/People_Management.aspx

Enz, C. A., \& Siguaw, J. (2003, Oct.-Dec.). Revisiting the best of the best: Innovations in hotel practice.: Cornell Hotel and Restaurant Administrative Quarterly. Ithica, NY

Gill, A.S., Flaschner, A.B. \& Shachar, M. (2006), Mitigating stress and burnout by implementing transformational-leadership, International Journal of Contemporary Hospitality Management, 18(6) 469-81.

Gursoy, D., \& Swanger, N. (2007). [Generational leadership in the hospitality workforce]. Unpublished raw data.

Gursoy, D., \& Maier, T., \& Chi, C. (2008). Generational differences: An examination of work values and generational gaps in the hospitality workforce. International Journal of Hospitality Management, 27, 448-458.

Halsell-Scott, S. (2008). Using a model of emotional intelligence domains to indicate transformational leaders in the hospitality industry. Journal of Human Resources in Hospitality \& Tourism, 7(1), 99.

Hinkin, T., \& Tracey, J. (2000). The cost of turnover: Putting the price on the learning curve. Cornell Hotel and Restaurant Administration Quarterly, 41(2),14-21.

Kozak \& Uka, (2008). Effective factors in the constitution of leadership styles: a study of Turkish hotel managers. Anatolia International Journal of Tourism and Hospitality, 19(2), 117-134. 


\section{Educational Research}

King, Funk \& Wilkins. (2011). Bridging the gap: An examination of the relative alignment of hospitality research and industry priorities. International journal of hospitality management, 30(1), 157-166.

Kim, H.J, \& Argusa, J. (2011). Hospitality service employees' coping styles: The role of emotional intelligence, two basic personality traits, and socio-demographic factors. International Journal of Hospitality Management, 30 588-598.

Kim, H.J., Shin, K.H., \& Umbreit, W.T. (2007). Hotel job burnout: the role of personality characteristics. International Journal of Hospitality Management 26(4), 421-434.

Kupperschmidt, B. R. (2000). Multigeneration employees: Strategies for effective management. The Health Care Manager, 19, 65-76.

Lucas, R., \& Deery, M. (2004). Significant Developments and Emerging Issues in Human Resource Development, Hospitality Management, 23, 459-472.

Masry, S., Kattara, H., \& Demerdash, J. (2004). A comparative study on leadership styles adopted by general managers: a case study in Egypt. Journal Anatolia, 15(2), 109-124.

Minett, D., Yaman, H.R, \& Denizci, B. (2009). Leadership styles and ethical decisionmaking in hospitality management. International Journal of Hospitality Management, 28(4), 486-493.

Mok, C., Pine, R., \& Pizam, A. (1998). Work values of Chinese hotel managers. Journal of Hospitality \& Tourism Research, 21(3), 1-16.

Ogaard, T., Marnburg, E., \& Larsen, S. (2007). Perceptions of organizational structure in the hospitality industry: Consequences for commitment, job satisfaction and perceived performance. Tourism Management, 29(4), 661-671.

Pittaway, L., Carmouche, R., \& Chell, E. (1998). The way forward: Leadership research in the hospitality industry. International Journal of Hospitality Management, 17(4), 407-426.

Sila, I., \& Ebrahimpour, M. (2004). An examination of quality management in luxury hotels. International Journal of Hospitality and Tourism Administration, 4(2), 33-59.

Smola, K. W. \& Sutton, C. D. (2002). Generational differences: Revisiting generational work values for the new millennium. Journal of Organizational Behavior, 23, 363-382.

Sosik. J. J., \& Megerian, T. E. (1999). Understanding leader emotional intelligence and performance. Group Â Organization Management, 24(3), 367-390.

Springston, J. (2011-March). Carlson Country. AAHOA Lodging business. 26-28. 
Examination of Hotel-Lodging Academic and Industry Leadership Practices in 12 Educational Research

Tracey, J.B., \& Hinkin, T.R. (1994). Transformational leaders in the hospitality industry. The Cornell Hotel and Restaurant Administration Quarterly, 35(2), 18-24.

Tracey, J.B., \& Hinkin, T.R. (1996). How transformational leaders lead in the hospitality industry, International Journal of Hospitality Management, 15(2),165-76.

Uhl-Bien, M., Marion, R., \& McKelvey, B. (2007). Complexity leadership theory: Shifting leadership from the industrial age to the knowledge era. The Leadership Quarterly, 18, 298-318.

White, C. (2006). Towards an understanding of the relationship between work values and cultural orientation. International Journal of Hospitality Management 25, 699715.

Wong, C . \& Law. K. S. (2002). The effects of leader and follower emotional intelligence on performance and attitude: An exploratory study. The Leadership Quarterly. 13(3), 243-274.

Zemke, R., Raines, C. \& Filipczak, B. (2000). Generations at work. New York: American Management Association.

Table 1

Hospitality-Academic Leadership Studies

\begin{tabular}{|l|l|}
\hline \multicolumn{1}{|c|}{ Leadership Style/Topic } & \multicolumn{1}{|c|}{ Reference } \\
\hline 1) Bureaucratic approach & $\begin{array}{l}\text { Pittaway, L., Carmouche, R., \& Chell, E. } \\
\text { (1998); Lucas \& Deery, 2004;Mok et al., } \\
\text { 1998; Tracey, \& Hinkin, 1994, 1996; Hinkin } \\
\text { and Tracey, (2000); (Borgatti, 2002). }\end{array}$ \\
\hline 2) Generational leadership & $\begin{array}{l}\text { Ogaard, Marnburg, \& Larsen, (2007); Uhl-Bien, } \\
\text { Marion, \& McKelvey, (2007); Minett, Yaman, } \\
\text { and Deniczki, (2009); Gursoy, et } \\
\text { al.,(2008);Cairncross \& Buultjens, 2007); Zemke et } \\
\text { al., (2000). }\end{array}$ \\
\hline 3) Transformational leadership & $\begin{array}{l}\text { (Gill et al., 2009) (Masry, Kattara, \& } \\
\text { Demerdash, 2004); (Kozak \& Uka, 2008); (Halsell, } \\
\text { 2008); Halsell-Scott, (2008); Brown, (2011). }\end{array}$ \\
\hline 4) Workforce engagement & $\begin{array}{l}\text { (Chu, 2007; Kim, Chin, \& Umbreit, 2007; } \\
\text { White, 2006); Brown (2002) and Chu (2007). }\end{array}$ \\
\hline 5) Emotional intelligence & (Kim and Argusa, 2011); (Langhorn, 2004). \\
\hline
\end{tabular}


Examination of Hotel-Lodging Academic and Industry Leadership Practices in 13 Educational Research

Table 2

Hospitality-Industry Leadership Best practices

\begin{tabular}{lllll}
\hline Best Practice & $\begin{array}{l}\text { Day } \\
\text { Hospitality }\end{array}$ & Carlson Hotels & Walt Disney & Marriott \\
& & \\
\hline
\end{tabular}

1) Leadership

$\mathrm{X}$

capability

2) Social media

$\mathrm{X}$

3) Transformational

$\mathrm{X}$

leadership

4) Learning

$\mathrm{X} \quad \mathrm{X}$

environments

5) Workforce

$\mathrm{X}$

$\mathrm{X}$

$\mathrm{X}$ engagement

6) Loyalty programs

$\mathrm{X}$

7) Work/life balance $X$

Table 3

Identified Gaps in Academic Research and Industry Leadership

\section{Identified Gaps in Academic Research and Industry Leadership \\ Academic Research \\ Industry Practices}

1. Bureaucratic leadership

1. Business acumen

2. Generational leadership

2. Work-life balance

3. Transformational leadership

3. Loyalty programs

4. Workforce engagement

4. Branding-Co-Branding

5. Emotional intelligence

5. Social-media 